Supporting Information (SI) for

\title{
Catalytic Hydrothermal Decarboxylation and Cracking of Fatty Acids and Lipids over Ru/C
}

\author{
Jing Zhang ${ }^{\dagger} \ddagger$, Xiangchen $\mathrm{Huo}^{\ddagger}$, Yalin $\mathrm{Li}^{\ddagger, \S}$, Timothy J. Strathmann ${ }^{\ddagger, s, *}$
}

${ }^{\dagger}$ Key Laboratory of the Three Gorges Reservoir Region’s Eco-Environment, Ministry of Education, College of Environment \& Ecology, Chongqing University, 83 Shabei Street, Chongqing 400045, PR China.

${ }^{\ddagger}$ Department of Civil and Environmental Engineering, Colorado School of Mines, 1500 Illinois

Street, Golden, Colorado 80401, United States.

${ }^{\S}$ Engineering Research Center for Re-inventing the Nation's Urban Water Infrastructure (ReNUWIt).

*Corresponding author: Timothy J. Strathmann, Email: strthmnn@ mines.edu.

This Supporting Information includes

7 pages

9 figures

1 table 
Table S1 Market prices of Pt, Ru, Pd and Rh.

\begin{tabular}{ccccc}
\hline Catalyst Metal & $\mathrm{Ru}$ & $\mathrm{Pt}$ & $\mathrm{Pd}$ & $\mathrm{Rh}$ \\
\hline${\text { Cost }\left(\$ \mathrm{US} \mathrm{troy} \mathrm{ounce}^{-1}\right)}$ & 270 & 859 & 1,175 & 2,550 \\
\hline
\end{tabular}

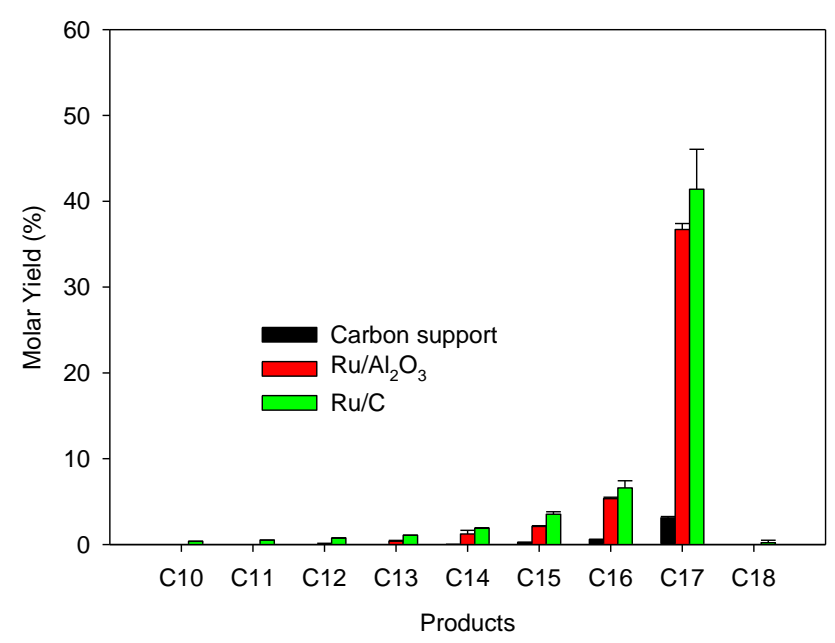

Figure S1 Liquid product molar yields (mol\%, n(product) $/ \mathrm{n}($ stearic acid) $\times 100 \%)$ over naked carbon support, $\mathrm{Ru} / \mathrm{Al}_{2} \mathrm{O}_{3}$ and $\mathrm{Ru} / \mathrm{C} . \mathrm{C}_{10}-\mathrm{C}_{18}$ labels refer to n-alkane products with 10 to 18 carbon atoms. Reaction conditions: $5 \mathrm{~g}$ stearic acid, $0.5 \mathrm{~g}$ catalyst, $80 \mathrm{~g} \mathrm{H}_{2} \mathrm{O}$, initial headspace gas $=1 \mathrm{MPa} \mathrm{N}_{2}$ at room temperature, preset reaction temperature $330{ }^{\circ} \mathrm{C}$, reaction time $5 \mathrm{~h}$.

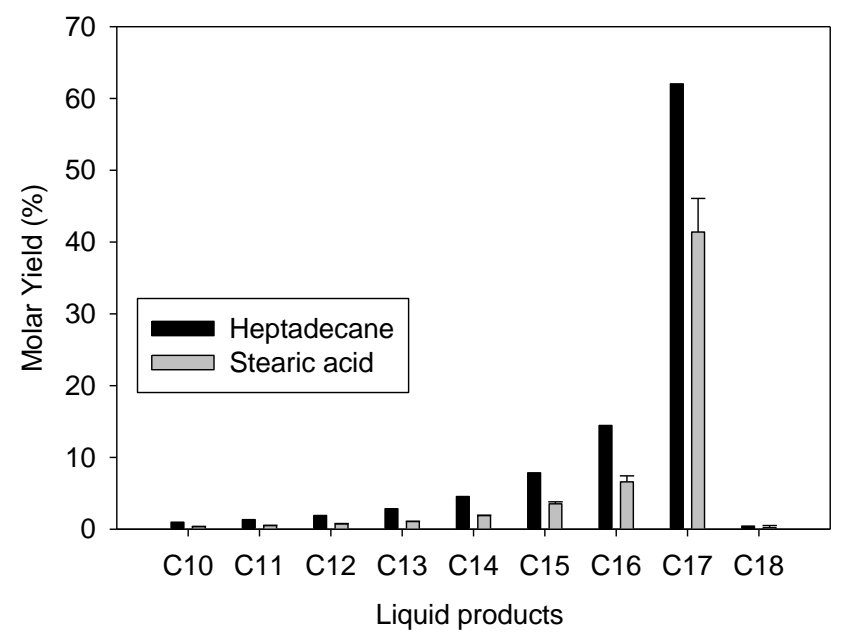

Figure S2 Comparison of the liquid product yields from hydrothermal reactions with $\mathrm{Ru} / \mathrm{C}$ initiated with either stearic acid $\left(\mathrm{CH}_{3}\left(\mathrm{CH}_{2}\right)_{16} \mathrm{COOH}\right)$ or heptadecane $\left(\mathrm{CH}_{3}\left(\mathrm{CH}_{2}\right)_{15} \mathrm{CH}_{3}\right)$ under $\mathrm{N}_{2}$ headspace gas. $\mathrm{C}_{10}-\mathrm{C}_{18}$ refer to n-alkane products with the indicated number of carbon atoms. Reaction conditions: $17.6 \mathrm{mmol} \mathrm{C}_{17}$ or stearic acid $(5 \mathrm{~g}, 17.6 \mathrm{mmol}), 0.5 \mathrm{~g}$ catalyst, $80 \mathrm{~g} \mathrm{H}_{2} \mathrm{O}$, initial headspace gas $=1 \mathrm{MPa} \mathrm{N} \mathrm{N}_{2}$ before heating to $330^{\circ} \mathrm{C}$. Reaction time $=5 \mathrm{~h}$. 

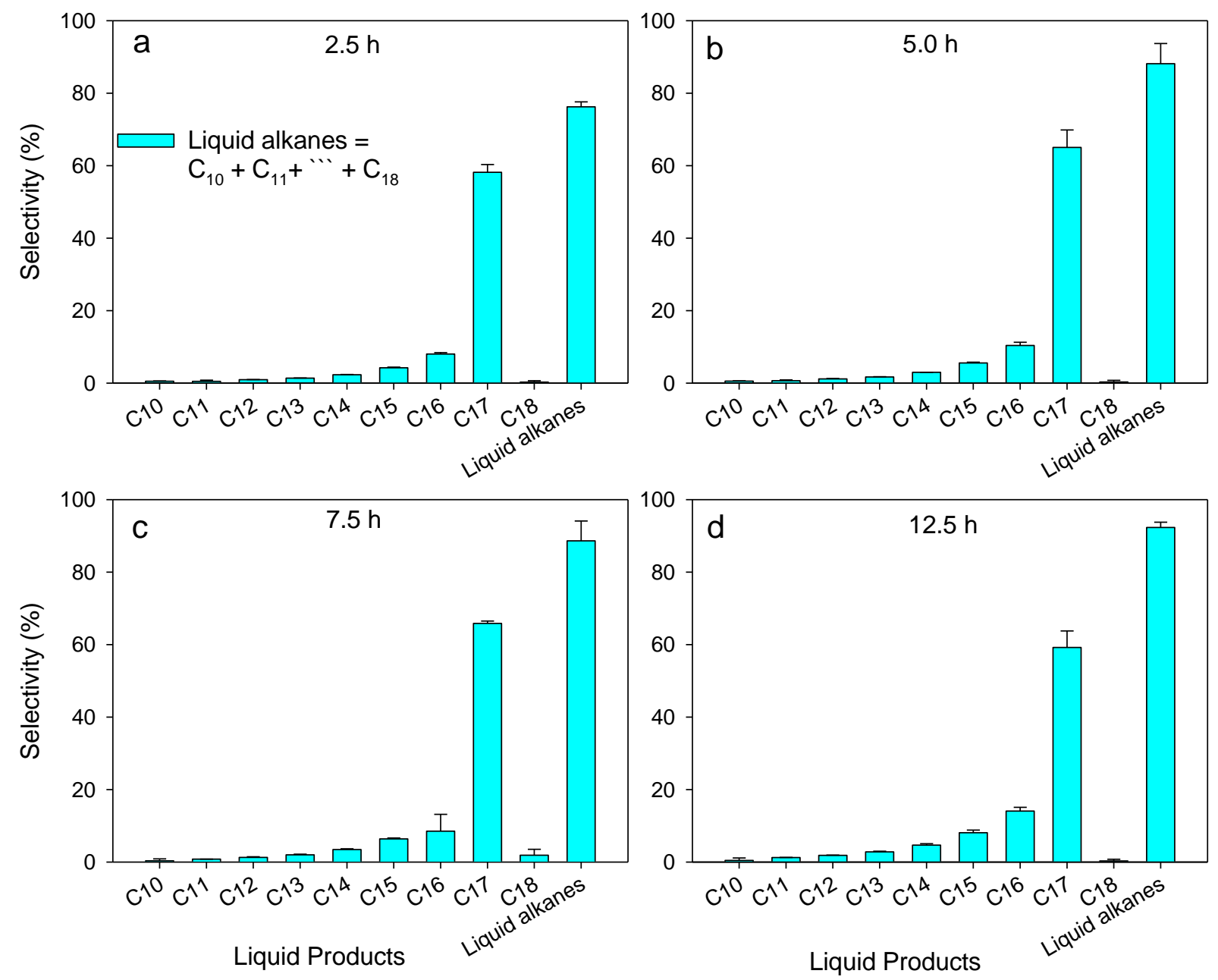

Figure S3 Temporal variation of alkane $\left(\mathrm{C}_{10}-\mathrm{C}_{18}\right)$ selectivity after DOX of stearic acid with $\mathrm{Ru} / \mathrm{C}$ for (a) $2.5 \mathrm{~h}$; (b) $5.0 \mathrm{~h}$; (c) $7.5 \mathrm{~h}$; and (d) $12.5 \mathrm{~h}$ under hydrothermal conditions. Bars labeled "liquid alkanes" represent the total $\mathrm{C}_{7}-\mathrm{C}_{17}, \mathrm{C}_{7}-\mathrm{C}_{9}$ alkanes were rarely detected, so selectivity for individual alkanes is only shown for $\mathrm{C}_{10}-\mathrm{C}_{17}$. Reaction conditions same as Figure 2 in the main text. 


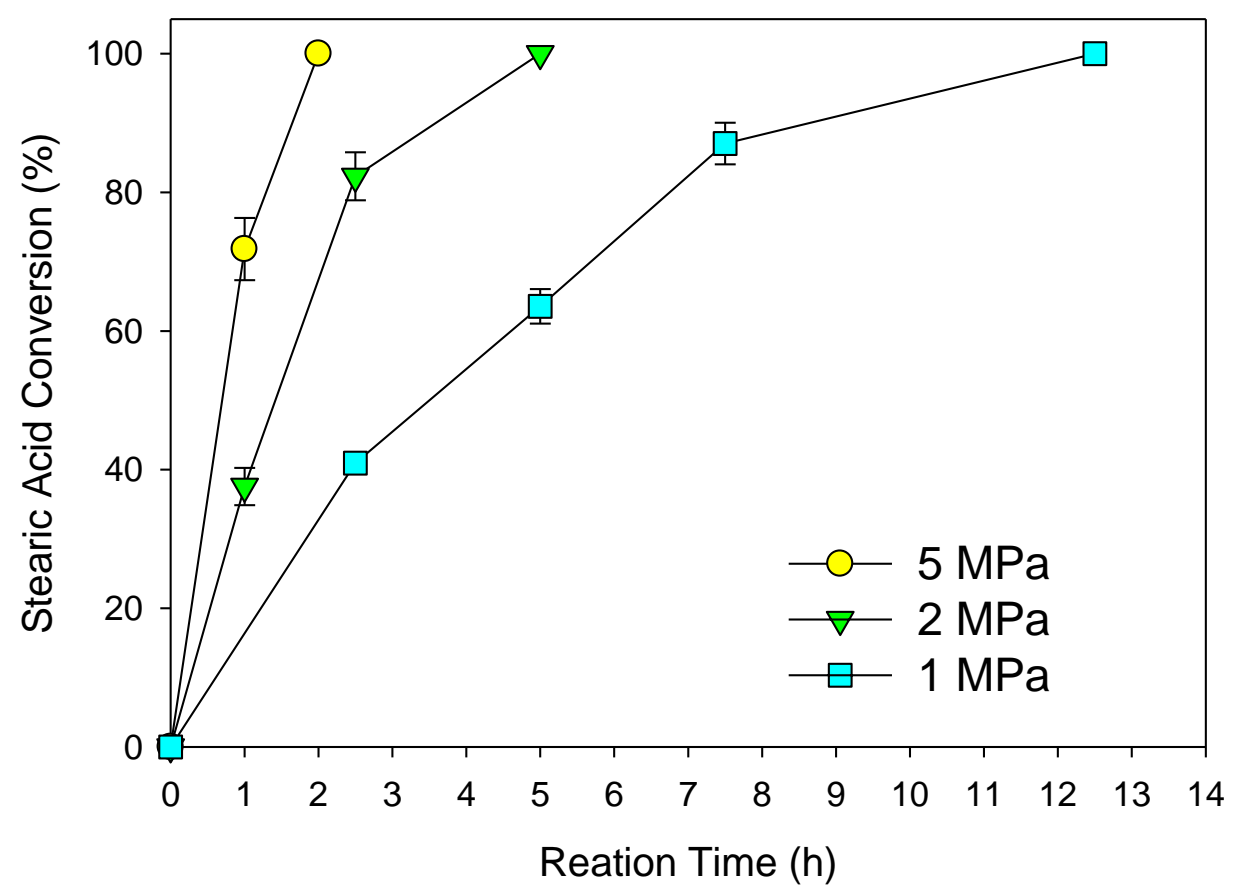

Figure $\mathbf{S 4}$ Effect of initial $\mathrm{N}_{2}$ headspace pressure on stearic acid conversion with $\mathrm{Ru} / \mathrm{C}$. Reaction conditions: $5 \mathrm{~g}$ stearic acid, $0.5 \mathrm{~g}$ catalyst, $80 \mathrm{~g} \mathrm{H}_{2} \mathrm{O}, 330^{\circ} \mathrm{C}$. Pressures indicate headspace pressure at ambient temperature before heating reactor to the set point temperature.

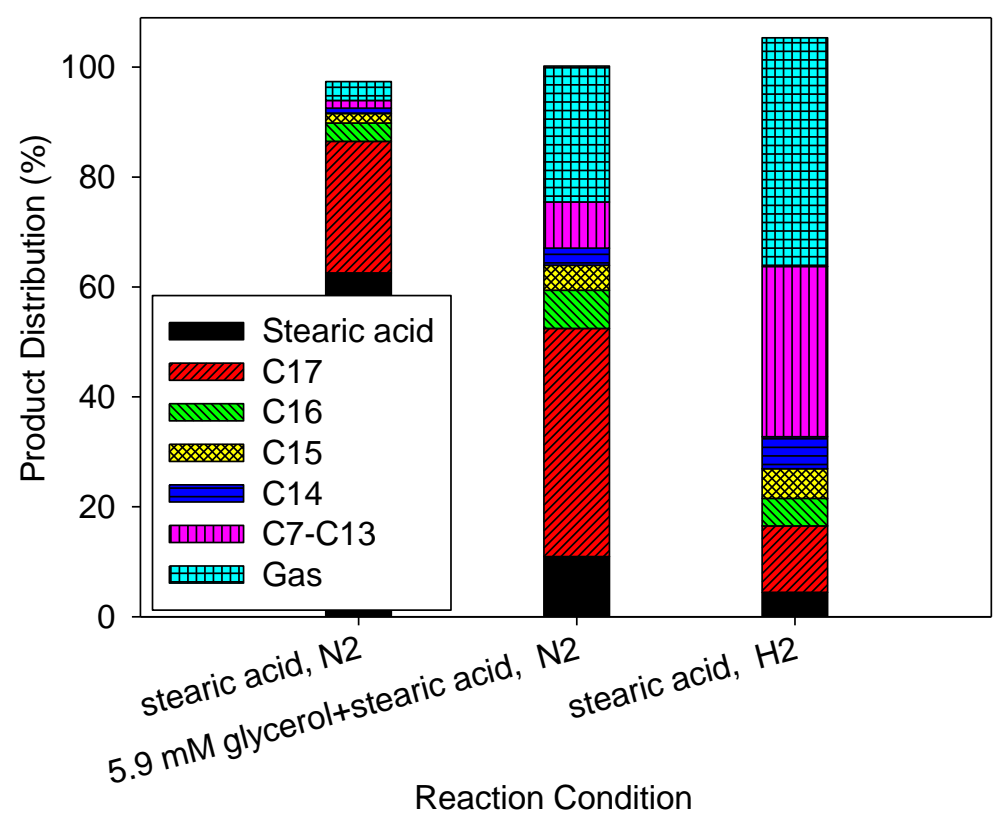

Figure S5 Influence of initial headspace gas and $\mathrm{H}_{2}$-producing reactor amendments on product distributions from hydrothermal conversion of stearic acid by Ru/C. Reaction conditions: $5 \mathrm{~g}$ stearic acid, $0.5 \mathrm{~g}$ catalyst, $80 \mathrm{~g} \mathrm{H}_{2} \mathrm{O}$, initial headspace gas $=2 \mathrm{MPa} \mathrm{N}_{2}$ or $\mathrm{H}_{2}$ before heating to $330{ }^{\circ} \mathrm{C}$, reaction time $1 \mathrm{~h}$. 

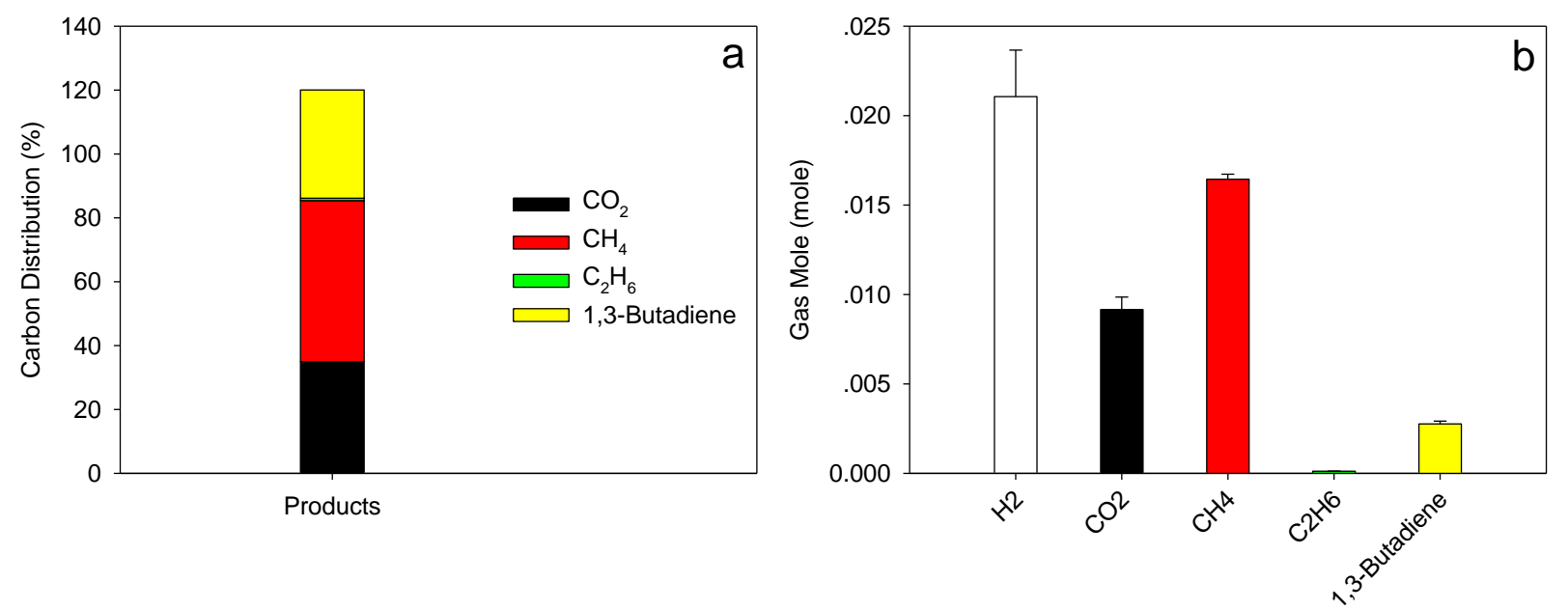

Figure S6 Gas products measured from hydrothermal conversion of glycerol with Ru/C. (a) distribution of feedstock carbon atoms detected within gas products; (b) overall moles of different gas products formed. Reaction conditions: $5.9 \mathrm{mmol}$ glycerol, $0.5 \mathrm{~g}$ catalyst, $80 \mathrm{~g} \mathrm{H}_{2} \mathrm{O}$, initial headspace gas $=2 \mathrm{MPa} \mathrm{N}$ before heating to $330^{\circ} \mathrm{C}$, reaction time $=1 \mathrm{~h}$.
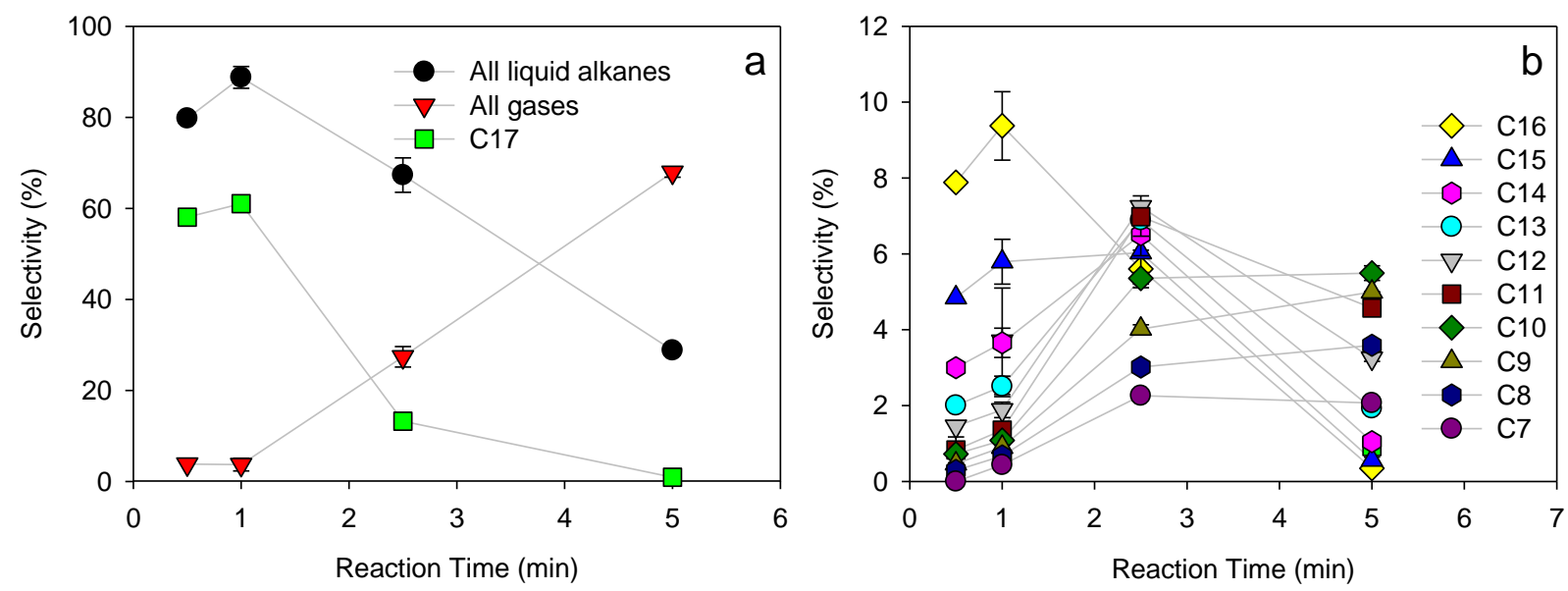

Figure S7 Temporal variation in alkanes and gas selectivity from hydrothermal conversion of stearic acid under $\mathrm{H}_{2}$ head gas with $\mathrm{Ru} / \mathrm{C} . \mathrm{C}_{7}-\mathrm{C}_{16}$ products are shown in separate panel $\mathrm{b}$ to better illustrate these products with selectivity $<10 \%$. Reaction conditions: Initial headspace gas $=1$ $\mathrm{MPa} \mathrm{H}_{2}$ before heating to $330{ }^{\circ} \mathrm{C}$, and other conditions the same as Figure 2. 


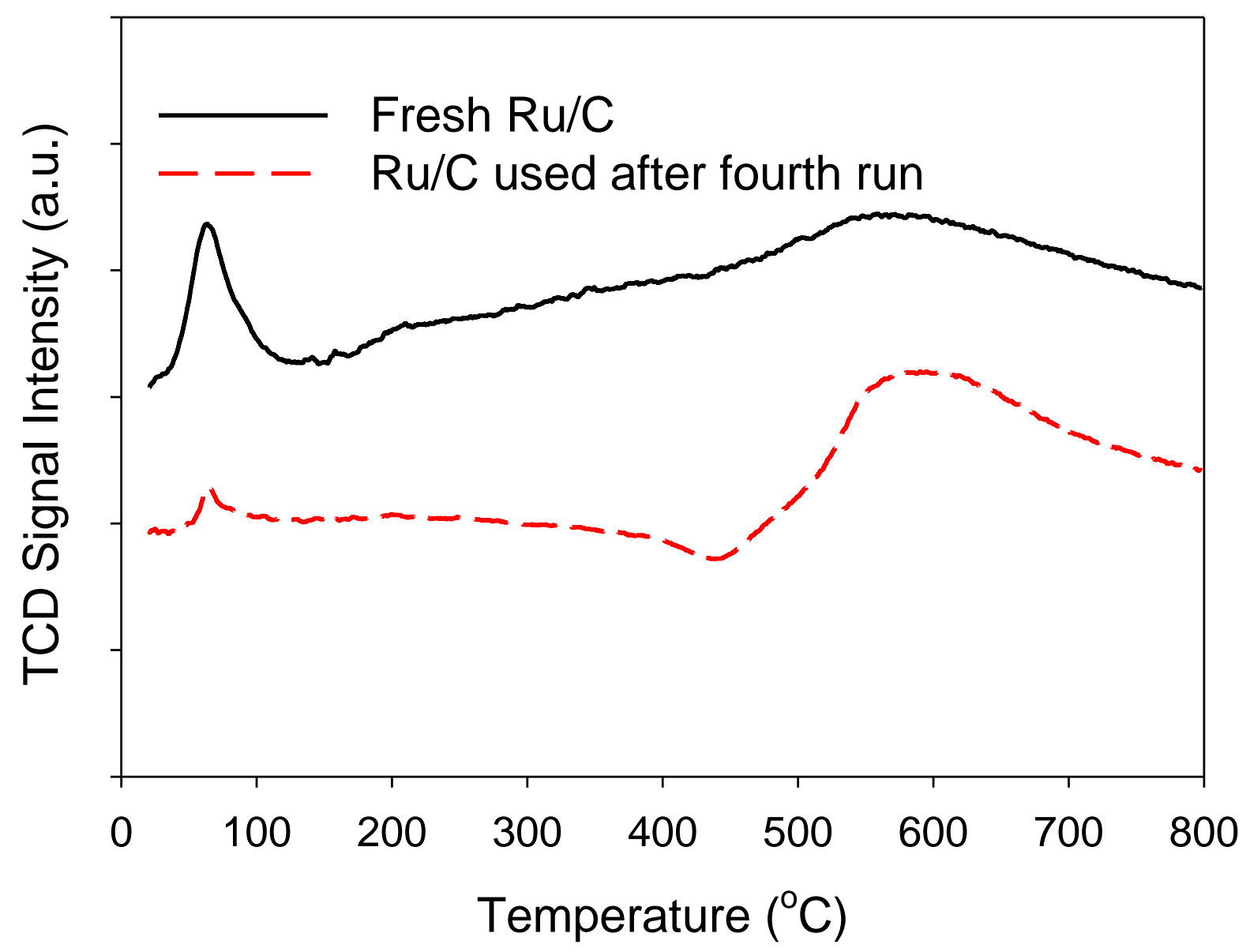

Figure S8 TPR profiles measured for fresh $\mathrm{Ru} / \mathrm{C}$ and $\mathrm{Ru} / \mathrm{C}$ following the fourth reaction cycle in the catalyst re-use experiment depicted in Figure 6. TCD signals are normalized with sample mass. 


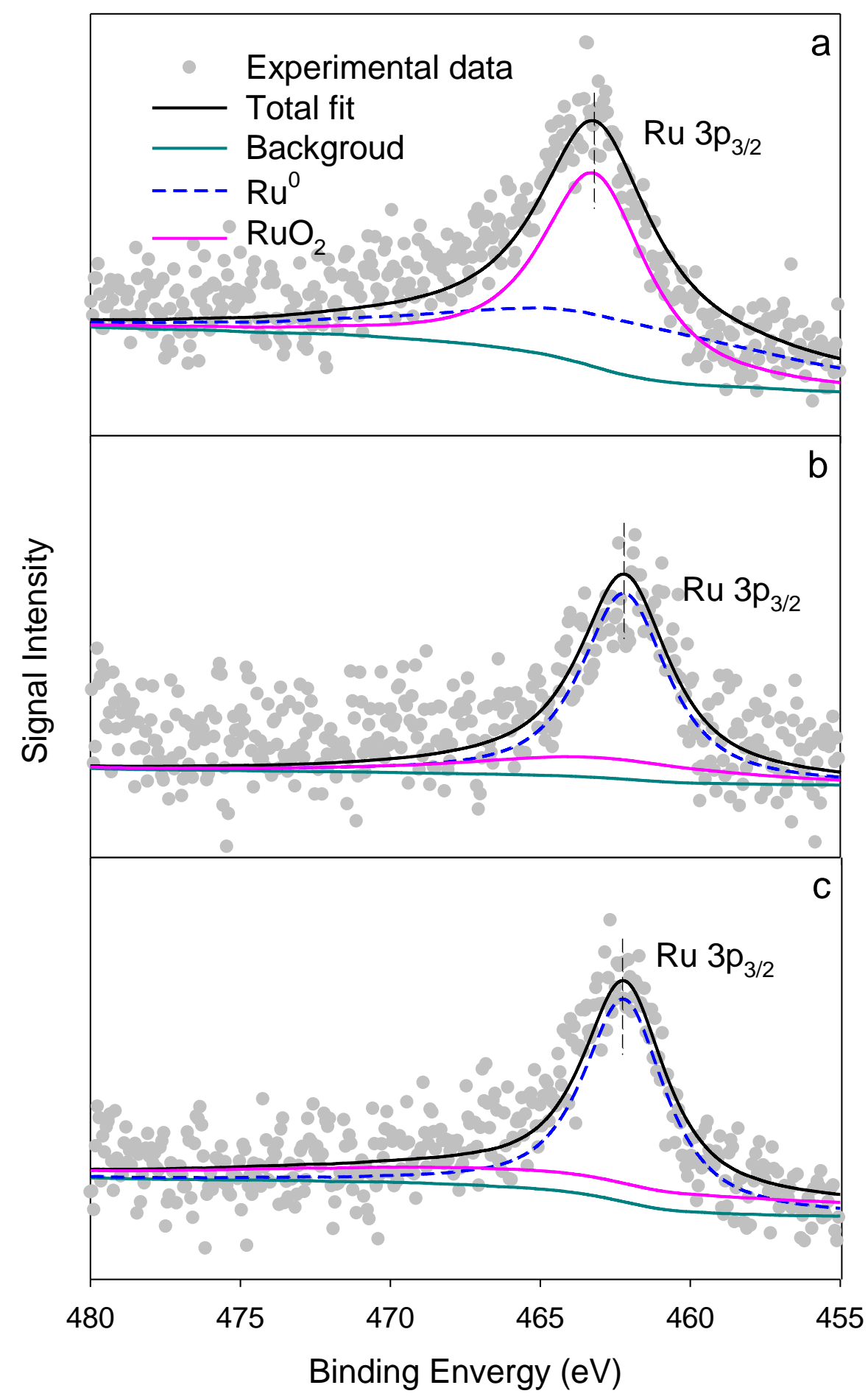

Figure S9 XPS of Ru/C samples from the catalyst re-use experiment, (a) fresh catalyst, (b) following the fourth reaction cycle, and (c) following ex-situ treatment with He before the fifth reaction cycle in the reuse experiment depicted in Figure 6. 